\title{
Factors influencing the self-reported sense of deviation in adults with successful surgical outcomes for strabismus
}

\author{
Na Ji ${ }^{1}$, Meiping $X u^{2}$, Huanyun $Y u^{2}$, Jinling $X u^{2}$ and Xinping $Y u^{2^{*}}$
}

\begin{abstract}
Background: To determine whether a sense of deviation remains in adults with successful motor alignment who fulfil diplopia criteria after surgery and to examine the factors associated with this judgement.

Methods: This was a retrospective study. Adult patients defined as having a successful outcome based on more than 1 year of post-operative follow-up visits were included in the study. The sense of deviation was determined at the last visit. Pre- and post-operative deviation and characteristics including age, gender, education level, occupation, diagnosis, size of deviation, extraocular movement (EOM), binocular function, and health-related quality of life (HRQOL) were recorded.

Results: In total, 22 (24\%) of the 91 adults with successful surgical outcomes reported a sense of deviation. No significant differences were noted between subjects with and without a sense of deviation regarding patient demographics, preand post-operative deviation, changes in deviation, sensory fusion or EOM. Subjects with a sense of deviation had an increased prevalence of and larger post-operative vertical deviation, poorer stereo function, and lower HRQOL scores than those with no sense of deviation. The presence of post-operative vertical deviation was associated with a sense of deviation.

Conclusions: Approximately one-fourth (24\%) of adults defined as having successful surgical outcomes who still had a sense of deviation exhibited worse stereo function, higher vertical deviation size and lower HRQOL scores. The presence of 3 to 5 prism dioptres $(\mathrm{pd})$ of vertical deviation would be the main factor associated with a sense of deviation post-operatively.
\end{abstract}

Keywords: Strabismus, Surgery, Self-sense, Outcome, Deviation

\section{Background}

Strabismus surgery in adults aims to improve ocular alignment, reduce diplopia, [1] and recover binocular function, $[2,3]$ with the benefit of improving psychosocial aspects of patients, e.g., social interactions, self-esteem, [4-7] and health-related quality of life (HRQOL) [8-10]. Patients with successful post-operative motor alignment have better HRQOL, which improves progressively after surgery $[6,7,9-11]$. The definition of successful alignment was inconsistent in previous studies(tropia within 8 to 12 prism dioptres (pd) horizontally and within 2 to $5 \mathrm{pd}$. or

\footnotetext{
*Correspondence: chnyu_xh@163.com

${ }^{2}$ The Eye Hospital of Wenzhou Medical University, No. 270, Xueyuan Xi Rd, Wenzhou 325027, China

Full list of author information is available at the end of the article
}

$10 \mathrm{pd}$. vertically) [12-16]. In addition, various discrepancies are consistently noted by patients and physicians in surgical outcome assessments [17]. Satterfield et al. found that greater than $80 \%$ of subjects thought that their eyes were still not perfectly straight; however, nearly all patients reported improved life after surgery [5]. Additionally, Hertle et al. reported highly subjective success in an adult group [16]. However, neither of these studies compared the patients' subjective senses of their surgical outcome with their motor alignment $[5,16]$. Self-esteem and characteristics associated with judgement in patients who undergo successful motor alignment after corrective surgery thus still require evaluation.

The present study evaluated the subjective self-sense of alignment with or without deviation in adults with 
successful motor alignment who fulfilled diplopia criteria after surgery, and the characteristic factors associated with their judgement were also studied.

\section{Methods}

\section{Patients and methods}

This retrospective study recruited adult patients who underwent corrective surgery at the Eye Hospital of Wenzhou Medical University between 1 January 2011 and 31 December 2011. All included patients underwent follow-up for more than 1 year and were defined as having a successful outcome at the last post-operative visit. Success was defined as no (or only "rare") diplopia/visual confusion for straight-ahead distances and for reading, with no greater than $10 \mathrm{pd}$. horizontal and $5.0 \mathrm{pd}$. vertical tropia in a primary position either close by or at a distance $[9,12]$. Patients were excluded from the study if they had diplopia or tropia that did not meet the success criteria or if they had associated facial deformities. The study was approved by the Eye Hospital of Wenzhou Medical University Ethics Committee and adhered to the tenets of the Declaration of Helsinki.

\section{Clinical assessment}

Full pre- and post-operative orthoptic measurements were recorded. Age, gender, education level, occupation, diagnosis, size of deviation, extraocular movement (EOM), and binocular function at the time of the survey were also recorded. Eye position was determined as tropia (constant/intermittent), phoria, or orthophoria using a cover test, and the deviation was measured using a prism and alternate cover test (PACT) at distances of $5 \mathrm{~m}$ and $40 \mathrm{~cm}$. Combined $(|\mathrm{dev}|)$ was calculated with horizontal $\left(\operatorname{dev}_{\mathrm{h}}\right)$ and vertical $\left(\operatorname{dev}_{\mathrm{v}}\right)$ deviations as $|\operatorname{dev}|=\sqrt{ }($ $\operatorname{dev}_{\mathrm{h}}{ }^{2}+\operatorname{dev}_{\mathrm{v}}{ }^{2}$ ) [10]. Sensory fusion was tested using the Worth 4-dot test, and stereo acuity was tested using TNO stereopsis tests. The Chinese version of the Adult Strabismus 20 (CAS-20) was also completed at the last visit to evaluate the HRQOL of the subjects [18]. The CAS-20 consists of 10 items in a psychosocial subscale and 10 items in a function subscale, each of the 20 questionnaire items was scored $(0,25,50,75$, or 100) according to a 5point (always, often, sometimes, rarely, or never, respectively) likert-type scale. The self-reported sense of deviation was assessed as "no deviation", "still have some deviation", or "still have obvious deviation" before any clinical examination was performed at the visit. Table 1 presents the characteristics assessed at the last visit.

\section{Analysis}

For the analysis, subjects with a response of "still have some deviation" or "still have obvious deviation" were grouped as having a "self-reported sense of deviation". The education level was classified as higher education or primary education (secondary education, primary education and illiteracy). An independent t-test was used to compare CAS scores, age, follow-up time, deviation, and the change in $|\mathrm{dev}|$ between the "self-reported sense of deviation" and "self-reported sense of no deviation" groups. The Chi-Square test was used to compare proportions between the groups, and if any of the groups have small numbers (ie expected cell sizes $<5$ ), the Fisher Exact Test would be used. Moreover, multivariate analysis of variance was used to evaluate the factors associated with different characteristics. All statistical analyses were performed using the SPSS 19.0 software package (SPSS Inc., Chicago, IL, USA).

\section{Results \\ Basic data}

A total of 91 patients aged 16 to 65 years old $(25.9 \pm 9.7)$ were included in the study, of whom 41 (45\%) were female. The follow-up time was 12 to 42 months $(17.6 \pm 4.7)$, and the median visual acuity was 20/20 (range: $20 / 100$ to $20 / 20$ ) in the better eye and 20/25 (range: no light perception to $20 / 20$ ) in the worse eye. In addition, 30 of the 91 subjects had visual deficits in one or both eyes. Of the 91 patients, 22(24\%)exhibited esotropia, 57(63\%)exhibited exotropia, and $12(13 \%)$ exhibited vertical deviation prior to surgery. The horizontal deviation decreased from $44.6 \pm 16.6 \mathrm{pd}$. pre-operatively to $2.3 \pm 3.4 \mathrm{pd}$. post-operatively, and the vertical deviation decreased from $3.1 \pm 6.8 \mathrm{pd}$. pre-

Table 1 Classification of associated factors

\begin{tabular}{ll}
\hline Factor & Classification \\
\hline EOM & Classified as normal, mildly abnormal (mild overaction or underaction) or obviously abnormal (obvious overaction or underaction) \\
Sensory fusion & Classified as normal or abnormal (suppression or diplopia) \\
Stereo acuity & Classified as normal stereo ( $\leq 60$ s of arc), partial normal stereo (120 to $480 \mathrm{~s}$ of arc), or none (> $480 \mathrm{~s}$ of arc) \\
Visual deficit & Defined as one or both eyes having a BCVA less than 20/60 \\
Education level & $\begin{array}{l}\text { Classified as higher education (college education and above), secondary education (community college and high school), } \\
\text { primary education (middle school and primary school), or illiteracy }\end{array}$ \\
Occupation & $\begin{array}{l}\text { Classified as work with people (e.g., teacher, salesperson) or work without addressing people (e.g., technician, cook, } \\
\text { construction worker) }\end{array}$
\end{tabular}


operatively to $0.5 \pm 1.3 \mathrm{pd}$. post-operatively, with a $|\mathrm{dev}|$ change of $43.4 \pm 17.1 \mathrm{pd}$. after surgery. At the last visit, 53(58\%)patients exhibited orthophoria, 18(20\%)patients exhibited phoria, 14(15\%)patients exhibited intermittent tropia, and 6(7\%)patients exhibited constant tropia or dissociated vertical deviation (DVD). 7(8\%)subjects had complaints of diplopia prior to surgery, and $9(10 \%)$ subjects exhibited diplopia at the periphery after surgery.

\section{Comparison between subjects with a sense of deviation and those without a sense of deviation}

Of the 91 subjects, 69 (76\%) reported no sense of deviation, and 22 (24\%) reported a sense of deviation (18 patients with a sense of some deviation and 4 patients with a sense of obvious deviation). No significant difference in the patient demographics was noted between the two groups (Table 2). Furthermore, no significant differences were noted regarding pre- and post-operative deviation, changes in deviation size, and post-operative horizontal deviation between the two groups (Table 3). Subjects with a sense of deviation had larger post-operative vertical deviation and an increased prevalence of vertical deviation compared with those with no sense of deviation (Table 3).

Table 3 indicates that subjects with no sense of deviation had better stereo function than those with a sense of deviation. No significant differences were noted in sensory fusion, EOM, or visual deficits between the two groups. Subjects with no sense of deviation had higher HRQOL scores, including scores for psychosocial aspects and functional aspects, than those with a sense of deviation.

\section{Factors associated with the sense of post-operative deviation}

Multivariate analysis of variance was used to analyse factors including gender, education level, pre- and postoperative deviation, binocular function, and EOM. Table 4 indicates that the presence of post-operative vertical deviation was associated with a sense of deviation. Furthermore, according to the post-operative vertical deviation, 91 subjects were divided into two groups, with 81 subjects in within $2 \mathrm{pd}$. vertical group and 10 subjects in within $5 \mathrm{pd}$. vertical group, respectively. There were significant differences in sensory fusion, Stereo function, HRQOL scores between two groups. The group of within $5 \mathrm{pd}$. vertical group had worse sensory fusion, Stereo function, lower HRQOL scores.

When success criteria of within $10 \mathrm{pd}$. horizontal and $2 \mathrm{pd}$. vertical deviations were applied in the study, $81 \mathrm{pa}$ tients would be included in the study as with successful alignment. Of whom 37 (46\%) were female, 20(25\%)exhibited esotropia, 54(66\%)exhibited exotropia, and $7(9 \%)$ exhibited vertical deviation prior to surgery. The horizontal deviation decreased from $47.6 \pm 16.7$ pd. preoperatively to $2.4 \pm 3.4 \mathrm{pd}$. post-operatively, and the vertical deviation decreased from $2.1 \pm 6.0$ pd. preoperatively to $0 \pm 0.2 \mathrm{pd}$. post-operatively, and only 1 subject exhibited post-operative vertical deviation. Of these 81 subjects, 68 (84\%) reported no sense of deviation, and $13(16 \%)$ reported a sense of deviation. No significant differences were noted in sensory fusion, Stereo function, EOM, visual deficits, and HRQOL scores between the two groups.

\section{Discussion}

In this study, we found that approximately $24 \%$ of adults still have a sense of deviation despite being classified as having a successful surgical outcome. Subjects with a self-reported sense of deviation exhibited worse stereo function, more vertical deviation, and worse HRQOL than those without a sense of deviation. The presence of vertical deviation was identified as a factor related to a sense of deviation.

Successful alignment criteria were not consistent in previous studies, as noted in Table 5 . Here, we used criteria for a successful outcome that included motor alignment and the desired diplopia (no diplopia/visual confusion at primary and reading positions) [9]. When we used the success criteria of within $10 \mathrm{pd}$. horizontal and 2 pd. vertical deviations, the incidence of selfreported sense of deviation would be reduced from 24 to $16 \%$. Furthermore, we didn't find any factors associated with subjects' sense of deviation.

Our study confirmed that surgical outcome assessment reveals different perspectives between patients and physicians. Beauchamp et al. found that a difference in severity ratings between patients and physicians improved

Table 2 Comparison between the demographic characteristics of the two groups

\begin{tabular}{|c|c|c|c|c|c|c|c|c|}
\hline & \multirow[t]{2}{*}{ Age $(y)$} & \multirow{2}{*}{$\begin{array}{l}\text { Follow-up time } \\
\text { (months) }\end{array}$} & \multicolumn{2}{|c|}{ Gender } & \multicolumn{2}{|c|}{ Education level } & \multicolumn{2}{|l|}{ Occupation } \\
\hline & & & Male & Female & $\begin{array}{l}\text { Higher } \\
\text { education }\end{array}$ & $\begin{array}{l}\text { Primary } \\
\text { education }\end{array}$ & Works with people & $\begin{array}{l}\text { Works without } \\
\text { addressing people }\end{array}$ \\
\hline $\begin{array}{l}\text { No sense of deviation } \\
(n=69)\end{array}$ & $26.3 \pm 10.2$ & $17.7 \pm 5.0$ & 34 & 35 & 19 & 50 & 54 & 15 \\
\hline $\begin{array}{l}\text { Sense of deviation } \\
(n=22)\end{array}$ & $24.4 \pm 8.1$ & $17.5 \pm 4.5$ & 16 & 6 & 6 & 16 & 19 & 3 \\
\hline$p$ value & $t=0.81, p=0.42$ & $\mathrm{t}=0.17, p=0.87$ & \multicolumn{2}{|c|}{$X^{2}=3.71, p=0.054$} & \multicolumn{2}{|c|}{$X^{2}=0.004, p=0.951$} & \multicolumn{2}{|l|}{$X^{2}=0.736, p=0.545$} \\
\hline
\end{tabular}


Table 3 Comparison of strabismus characteristics between the two groups

\begin{tabular}{|c|c|c|c|}
\hline & $\begin{array}{l}\text { No sense of deviation } \\
(n=69)\end{array}$ & $\begin{array}{l}\text { Sense of deviation } \\
(n=22)\end{array}$ & $P$ value \\
\hline Pre-operative |dev| (pd) & $47.1 \pm 15.4$ & $42.7 \pm 20.6$ & $\mathrm{t}=1.1, p=0.28$ \\
\hline Post-operative |dev| (pd) & $2.6 \pm 3.5$ & $3.1 \pm 3.0$ & $\mathrm{t}=0.7, p=0.49$ \\
\hline Change in |dev| (pd) & $44.6 \pm 16.0$ & $39.6 \pm 20.2$ & $\mathrm{t}=1.2, p=0.24$ \\
\hline Post-operative horizontal deviation (pd) & $2.5 \pm 3.5$ & $1.6 \pm 2.9$ & $t=1.0, p=0.30$ \\
\hline Post-operative vertical deviation (pd) & $0.06 \pm 0.5$ & $1.8 \pm 2.1$ & $\mathrm{t}=6.3, p<0.001$ \\
\hline \multicolumn{4}{|l|}{ CAS-20 } \\
\hline Psychosocial aspects & $81.4 \pm 14.8$ & $70.2 \pm 16.8$ & $\mathrm{t}=3.0, p=0.04$ \\
\hline Functional aspects & $73.2 \pm 13.4$ & $62.2 \pm 16.6$ & $\mathrm{t}=3.2, p=0.02$ \\
\hline Total score & $77.3 \pm 13.2$ & $66.2 \pm 15.0$ & $\mathrm{t}=3.3, p=0.001$ \\
\hline \multicolumn{4}{|l|}{ Post-operative vertical deviation (n) } \\
\hline With & 1 & 10 & \multirow[t]{2}{*}{$X^{2}=30.3, p<0.001$} \\
\hline Without & 68 & 12 & \\
\hline \multicolumn{4}{|l|}{ EOM (n) } \\
\hline Normal & 53 & 14 & \multirow[t]{2}{*}{$X^{2}=1.5, p=0.22$} \\
\hline Abnormal & 16 & 8 & \\
\hline \multicolumn{4}{|l|}{ Sensory fusion (n) } \\
\hline Normal & 32 & 8 & \multirow[t]{2}{*}{$X^{2}=0.68, p=0.41$} \\
\hline Abnormal & 37 & 14 & \\
\hline \multicolumn{4}{|l|}{ Stereo function (n) } \\
\hline Normal/partial Normal & 34 & 5 & \multirow[t]{2}{*}{$X^{2}=4.8, p=0.028$} \\
\hline None & 35 & 17 & \\
\hline \multicolumn{4}{|l|}{ Visual deficit (n) } \\
\hline With & 22 & 8 & \multirow[t]{2}{*}{$X^{2}=0.2, p=0.69$} \\
\hline No & 47 & 14 & \\
\hline
\end{tabular}

Table 4 Factors associated with the sense of deviation

\begin{tabular}{|c|c|c|c|c|c|}
\hline Source & Type III sum of squares & $\mathrm{df}$ & Mean square & $\mathrm{F}$ & $p$ \\
\hline Corrected model & $6.623 a$ & 16 & 0.414 & 3.022 & 0.001 \\
\hline Intercept & 0.275 & 1 & 0.275 & 2.010 & 0.16 \\
\hline Gender & 0.003 & 1 & 0.003 & 0.019 & 0.89 \\
\hline Occupation & 0.154 & 1 & 0.154 & 1.124 & 0.29 \\
\hline Education level & 0.002 & 1 & 0.002 & 0.017 & 0.90 \\
\hline $\begin{array}{l}\text { Direction of deviation } \\
\text { Pre-operative }\end{array}$ & 0.092 & 2 & 0.046 & 0.336 & 0.72 \\
\hline Pre-operative diplopia & 0.039 & 1 & 0.039 & 0.281 & 0.60 \\
\hline Pre-operative stereo function & 0.054 & 1 & 0.054 & 0.396 & 0.53 \\
\hline Visual deficit & 0.091 & 1 & 0.091 & 0.667 & 0.42 \\
\hline Post-operative presence of horizontal deviation & 0.011 & 1 & 0.011 & 0.077 & 0.78 \\
\hline Post-operative presence of vertical deviation & 1.916 & 1 & 1.916 & 13.988 & .000 \\
\hline EOM & 0.073 & 1 & 0.073 & 0.530 & 0.47 \\
\hline Post-operative diplopia & 0.243 & 1 & 0.243 & 1.773 & 0.19 \\
\hline Sensory fusion & 0.018 & 1 & 0.018 & 0.128 & 0.72 \\
\hline Post-operative stereo function & 0.306 & 1 & 0.306 & 2.236 & 0.14 \\
\hline Post-operative eye position & 0.002 & 1 & 0.002 & 0.014 & 0.91 \\
\hline
\end{tabular}


Table 5 Comparison of motor alignment criteria between the present study and previous studies

\begin{tabular}{lll}
\hline & \multicolumn{2}{l}{ Motor alignment (pd) } \\
\cline { 2 - 3 } & Horizontal & Vertical \\
\hline Our study & $\leq 10$ & $\leq 5$ \\
American Academy of Ophthalmology [1] & $\leq 12$ & $\leq 4$ \\
Keech et al. [12] & $\leq 10$ & $\leq 5$ \\
Zhang et al. [15] & $\leq 10$ & $\leq 2$ \\
Carruthers et al. [19] & $\leq 10$ & $\leq 10$ \\
Hertle et al. [13] & $\leq 12$ & $\leq 5$ \\
Beauchamp et al. [14] & $\leq 8$ & $\leq 2$ \\
Hatt et al. [16] & $\leq 10$ & $\leq 10$ \\
\hline
\end{tabular}

after surgery [17]. A lower percentage of subjects reported a sense of deviation after surgery in our study than in a report by Satterfield et al., where in $84 \%$ of subjects reported a sense of deviation. However, this group did not assess the actual deviation of the subjects, and the subjects reported an inability to perform stereo tasks and an inability to use both eyes together in that study [5]. Moreover, 23\% $(5 / 22)$ and $36 \%(8 / 22)$ of subjects with a sense of deviation had normal/partial normal stereo function and sensory fusion, respectively, in our study.

We report that changes in deviation and postoperative horizontal deviation did not differ between subjects in the two groups. A previous study demonstrated no significant correlation between psychosocial distress and deviation changes after surgery, whereas social anxiety and social avoidance (assessed using the Derriford Appearance Scale (DAS-24)) were both correlated with post-operative deviation and subjective strabismus severity (assessed via visual analogue scale (VAS)). However, the correlation between objective deviation size and subjective strabismus severity was not assessed in that study [7].

Female gender and a lower socioeconomic status have been associated with worse psychosocial aspects preoperatively and/or post-operatively $[10,20]$. We identified no significant difference in demographics, e.g., gender, age, occupation and education level, between subjects with and without a sense of deviation, although socioeconomic status as well as social anxiety was not reviewed in the current study. Social anxiety levels have also been reported be related to post-operative HRQOL in adult patients [21].

Post-operative HRQOL, as assessed using the CAS-20, was enhanced in subjects with no sense of deviation compared with those with a sense of deviation in the present study. This finding implies that post-operative HRQOL assessment can be applied as a criterion to evaluate the subjective outcome of surgery. As recent studies have suggested that motor alignment criteria cannot comprehensively represent a patient's postoperative status, this information combined with HRQOL tests may serve as a more useful method to evaluate successful outcome judgements $[9,22]$.

The presence of vertical deviation was identified as a factor related to the sense of deviation in the current study. Compared with the post-op within 2 pd. vertical group, the post-op within $5 \mathrm{pd}$. vertical group had worse sensory fusion, worse stereo function and lower HRQOL scores. In clinical work, these 3 to 5 pd. vertical deviations (including a certain degree of phoria) were not obvious in appearance when combined with multiplanar deviations, especially with a large angle horizontal deviation. Although approximately 45\% (10/22) of subjects with a self-reported sense of deviation exhibited a small vertical deviation, it is possible that this small vertical deviation could lead to asthenopia [23] or abnormal head posture [24]. However, asthenopia and abnormal head posture were not assessed in the current study. This finding also implied that even a small vertical deviation should be treated comprehensively.

There were some limitations to this study. First, we used criteria for a successful outcome that included motor alignment (no greater than $10 \mathrm{pd}$. horizontal and 5 pd. vertical deviations) and the desired diplopia (no diplopia/visual confusion at primary and reading positions), whereas some previous studies use a lower threshold for vertical alignment $(2 \mathrm{pd})$. When we used the stricter definition (within $10 \mathrm{pd}$. horizontal and $5 \mathrm{pd}$. vertical deviations), we didn't find any factors associated with subjects' sense of deviation. Further evaluations should be combined with more factors in future studies.

Second, although social anxiety levels have been reported to be related to the judgement of post-operative HRQOL in adult patients [21] and although psychosocial characteristics are thought to play a more important role than clinical aspects in the well-being of populations with strabismus, [25] we did not review psychosocial features, e.g., social anxiety and depression, we also did not review other factors that may influence the patient's perspective, such as palpebral fissure width, persistent redness of the conjunctiva in the current study.

\section{Conclusions}

In sum, approximately one-fourth of adults with successful surgical outcomes experience a sense of deviation. Subjects with a self-reported sense of deviation had worse stereo function, a larger vertical deviation size and lower HRQOL scores. The presence of 3 to $5 \mathrm{pd}$. vertical deviation would be the main factor related to the sense of deviation after successful surgery. We should use the stricter definition (within $10 \mathrm{pd}$. horizontal and $5 \mathrm{pd}$. vertical deviations) as the success criteria to assess the surgical outcome in clinic work. 


\section{Abbreviations}

CAS-20: The Chinese version of the Adult Strabismus 20; EOM: Extraocular movement; HRQOL: Health-related quality of life; PACT: A prism and alternate cover test

\section{Acknowledgements}

The authors thank Yajing Zhang, Ge Chen, Xiao Wu for their help in statistical advice and conducting the statistical analysis.

\section{Authors' contributions}

All authors contributed to this manuscript. The manuscript was written by NJ and reviewed by XPY. The experiment was designed by XPY. The materials and data were collected by NJ, MPX, HYY, JLX and XPY. All authors read and approved the final manuscript.

\section{Funding}

The research was supported by the Jiangsu Overseas Research and Training Program for University Prominent Young and Middle-aged Teachers and Presidents. The funder was not involved in the design of the study and collection, analysis, and interpretation of data and in writing the manuscript. The funder helped us get efficient and professional edit from English-editing company (AJE).

\section{Availability of data and materials}

The datasets used and analysed during the current study are available from the corresponding author on reasonable request.

\section{Ethics approval and consent to participate}

The study was approved by Ethics Committee of Eye Hospital of Wenzhou Medical University. All participants were according to the Declaration of Helsinki document on human research ethics, and underwent both verbal and written informed consents for participation by themselves or their guardians. Written informed consents were obtained from the participants or their parent in the case of children under 16 for publication of this study.

\section{Consent for publication}

Not applicable.

\section{Competing interests}

The authors declare that they have no competing interests.

\section{Author details}

${ }^{1}$ The affiliated Eye Hospital of Suzhou Vocational Health College; i.e. the affiliated Suzhou Eye Hospital of Wenzhou Medical University, Suzhou, China. ${ }^{2}$ The Eye Hospital of Wenzhou Medical University, No. 270, Xueyuan Xi Rd, Wenzhou 325027, China.

Received: 22 October 2018 Accepted: 30 December 2019

Published online: 06 January 2020

\section{References}

1. Mills MD, Coats DK, DonahueSP WDT. Strabismus surgery for adults: a report by the American Academy of ophthalmology. Ophthalmology. 2004;111: 1255-62. https://doi.org/10.1016/j.ophtha.2004.03.013.

2. Kushner BJ, Morton GV. Postoperative binocularity in adults with longstanding strabismus. Ophthalmol. 1992;99:316-9. https://doi.org/10. 1016/ S0161-6420(92)31970-0.

3. Lal G, Holmes JM. Postoperative stereo acuity following realignment for chronic acquired strabismus in adults. J AAPOS. 2002;6:233-7. https://doi org/10.1067/ mpa.2002.123399.

4. Xu J, Yu X, Huang Y, Chen J, Yu H, Wang Y, et al. The psychosocial effects of strabismus before and after surgical correction in Chinese adolescents and adults. J Pediatr Ophthalmol Strabismus. 2012;49:170-5. https://doi.org/10. 3928/ 01913913-20110920-02

5. Satterfield D, Keltner JL, Morrison TL. Psychosocial aspects of strabismus study. Arch Ophthalmol. 1993;111:1100-5. https://doi.org/10.1001/archopht. 1993. 01090080096024

6. Burke JP, Leach CM, Davis H. Psychosocial implications of strabismus surgery in adults. J Pediatr Ophthalmol Strabismus. 1997:34:159-64. https://doi.org/ 10.3928/ 0191-3913-19970501-06.
7. Jackson S, Harrad RA, Morris M, Rumsey N. The psychosocial benefits of corrective surgery for adults with strabismus. Br J Ophthalmol. 2006;90:883-8. https://doi.org/10.1136/bjo.2005.089516.

8. Hatt SR, Leske DA, Holmes JM. Responsiveness of health-related quality-oflife questionnaires in adults undergoing strabismus surgery. Ophthalmol. 2010;117:2322-8. https://doi.org/10.1016/j.ophtha.2010.03.042.

9. Hatt SR, Leske DA, Liebermann L. Changes in health-related quality of life 1 year following strabismus surgery. Am J Ophthalmol. 2012;153:614-9. https://doi.org/10.1016/j.ajo.2011.10.001.

10. Glasman P, Cheeseman R, Wong V, Young J, Durnian JM. Improvement in patients' quality-of-life following strabismus surgery: evaluation of postoperative outcomes using the adult strabismus 20 (AS-20) score. Eye (Lond). 2013;27:1249-53. https://doi.org/10.1038/eye.2013.174.

11. Dickmann A, Aliberti S, Rebecchi MT, Aprile I, Salerni A, Petroni S, et al Improved sensory status and quality-of-life measures in adult patients after strabismus surgery. J AAPOS. 2013;17:25-8. https://doi.org/10.1016/j.jaapos. 2012. 09.017.

12. Keech RV, Scott WE, Christensen LE. Adjustable suture strabismus surgery. J Pediatr Ophthalmol Strabismus. 1987;24:97-102. https://doi. org/10.3928/0191-3913.

13. Hertle RW. Clinical characteristics of surgically treated adult strabismus J Pediatr Ophthalmol Strabismus. 1998:35:138-45. https://doi.org/10. 3928/0191-3913.

14. Beauchamp GR, Black BC, Coats DK, Enzenauer RW, Hutchinson AK, Saunders RA, et al. The management of strabismus in adults--I. clinical characteristics and treatment. J AAPOS. 2003;7:233-40. https://doi.org/10. 1016/mpa. 2003.S1091853103001125.

15. Zhang MS, Hutchinson AK, Drack AV, Cleveland J, Lambert SR. Improved ocular alignment with adjustable sutures in adults undergoing strabismus surgery. Ophthalmology. 2012;119:396-402. https://doi.org/10.1016/j.ophtha. 2011.07. 044.

16. Hatt SR, Leske DA, Liebermann L, Holmes JM. Comparing outcome criteria performance in adult strabismus surgery. Ophthalmology. 2012;119:1930-6. https://doi.org/10.1016/j.ophtha.2012.02.035

17. Beauchamp GR, Black BC, Coats DK, Enzenauer RW, Hutchinson AK, Saunders RA, et al. The management of strabismus in adults--II. Patient and provider perspectives on the severity of adult strabismus and on outcome contributors. J AAPOS. 2005;9:141-7. https://doi.org/10.1016/j.jaapos.2004.11.015.

18. Yu H, Yang X, Ye T, Chen J, Zhang F, Yu X. Development and evaluation of a Chinese version of the adult strabismus questionnaire (AS-20). Ophthalmic Epidemiol. 2013;20:239-47. https://doi.org/10.3109/09286586.2013.809771.

19. Carruthers JD, Kennedy RA, Bagaric D. Botulinum vs adjustable suture surgery in the treatment of horizontal misalignment in adult patients lacking fusion. Arch Ophthalmol. 1990;108:1432-5. https://doi.org/10.1001/ archopht.1990.010701200 80033

20. Durnian JM, Owen ME, Baddon AC, Noonan CP, Marsh IB. The psychosocial effects of strabismus: effect of patient demographics on the AS-20 score. J AAPOS. 2010:14:469-71. https://doi.org/10.1016/j.jaapos.2010.08.013.

21. Alpak G, Coskun E, Erbagcil BY, Okumus S, Oren B, et al. Effects of corrective surgery on social phobia, psychological distress, disease-related disability and quality of life in adult strabismus patients. Br J Ophthalmol. 2014;98: 876-9. https://doi.org/10.1136/ bjophthalmol-2014-304888.

22. Hatt SR, Leske DA, Liebermann L, Holmes JM. Incorporating health-related quality of life into the assessment of outcome following strabismus surgery. Am J Ophthalmol. 2016;164:1-5. https://doi.org/10.1016/j.ajo.2015.12.029.

23. Archer SM. Small deviations: vertical, horizontal, and combined. Am Orthopt J. 2015:65:31-6. https://doi.org/10.3368/aoj.65.1.31.

24. Santiago AP, Rosenbaum AL. Dissociated vertical deviation and head tilts. J AAPOS. 1998:2:5-11. https://doi.org/10.1016/S1091-8531(98)90103-3.

25. McBain HB, Mackenzie KA, AuC HJ, Ezra DG, Adams GG, et al. Factors associated with quality of life and mood in adults with strabismus. Br J Ophthalmol. 2014:98: 550-5. https://doi.org/10.1136/bjophthalmol-2013-304220.

\section{Publisher's Note}

Springer Nature remains neutral with regard to jurisdictional claims in published maps and institutional affiliations. 